\title{
LOS ESPECTROS DEL SER ENTRE HEIDEGGER Y DERRIDA
}

\section{THE SPECTERS OF BEING BETWEEN HEIDEGGER AND DERRIDA}

\author{
Pablo B. SÁNCHEz Gómez* \\ UNED
}

\begin{abstract}
Resumen: En este texto se lleva a cabo una lectura de la obra de Martin Heidegger y Jacques Derrida tomando como eje la noción de "espectralidad". Se comprueba cómo ambos autores comprenden el pasado como aquello que debe ser heredado desde la creación y no simplemente como algo que se recibiría pasiva o mecánicamente. El espectro, por tanto, es este "origen" que "no es" y que se entrega como porvenir, como tarea. Sin embargo, es precisamente esta coincidencia la que distancia absolutamente el pensamiento de Derrida de la experiencia heideggeriana de la imposibilidad del espectro, es decir, de la aporía de su identidad.
\end{abstract}

PALABRAS ClaVE: aporía; espectro; herencia; imposibilidad.

AвstRACt: This paper carries out a reading of Martin Heidegger and Jacques Derrida taking as key the concept of "spectrality". It stands out how both authors think the past as an inheritance which must be created and not just as something which would be passively or mechanically accepted. The specter is this "origin" which "is not" and which gives itself as becoming, as task. However, it is precisely this coincidence between them which splits totally Derrida's thought from Heideggerian experience of the specter's impossibility, that is to say, of the aporia of its identity.

KeYwORDs: aporia; inheritance; impossibility; specter.

\footnotetext{
* Personal Investigador en Formación (FPI-UNED). psanchez@fsof.uned.es HTTPS://ORCID.ORG/0000-0002-2880-9704
} 
En su curso del año 1934 dedicado al poema de Hölderlin «Germania» señala Heidegger que "Die Schatten derer, so gewesen sind, besuchen uns neu, kommen auf uns zu, sind zu-künftig» ${ }^{1}$ (Heidegger, 1999: 107). Esta afirmación se inserta en la reflexión que Heidegger emprende desde 1934 hasta 1942 en torno a la búsqueda y conquista de la tierra natal (Heimat) del pueblo alemán, así como en torno a la capacidad del río Ister de remontar hasta su fuente (Quelle) en el curso de su historia. En este sentido, señala Heidegger que aquello que ya ha sido, el pasado, el origen (Ursprung) mismo, la fuente desde la cual nos constituimos, no es sencillamente algo disponible ahí a la mano (Zuhandenheit) en una suerte de «stock mnésico» que siempre podría ser representado inmediatamente en el recuerdo sino, por el contrario, una irrupción, un retornar (...besuchen uns neu) desde el pasado que se sitúa frente a nosotros como algo que procede del por-venir (...sind zu-künftig), como algo que se encuentra en trayecto desde el todavía-no y que se presenta como "sombra» (Schatten), esto es, como algo imposible de ser definido con claridad en su identidad o propiedad. El pensamiento en torno al origen o lo original es, por tanto, un pensamiento dedicado a la espectralidad, a lo que no es perfectamente presente, a lo que comienza por retornar. De este modo, como destaca Heidegger desde Hölderlin, los hombres y el río Ister no disponen de lo suyo más propio, no tienen en propiedad su origen, su «territorio esencial» (Wesenbereich) de una forma inmediata (sogleich), por lo que pertenecen (gehört) a la tierra natal (Heimat) sin encontrarse "propiamente» en ella, sin habitarla "en propiedad», pues ésta se halla, verdaderamente, en camino, se asigna como aquello que todavía está por venir, como aquello que no termina de llegar².

Esta aporía que supondría que los hombres se encuentran en lo más propio, en su origen y en su tierra natal sin disponer no obstante de ello puede leerla Heidegger en los versos de Hölderlin «nemlich zu Hauß ist der Geist / nicht im

1 «Las sombras de aquellos que han sido nos visitan nuevamente, vienen hacia nosotros, son por-venir».

2 Esta idea de la copertenencia entre el río Ister y los hombres en cuanto trayecto y travesía a lo natal lo señala Heidegger del siguiente modo: «el río determina el encontrarse en casa (Heimischsein) del ser humano histórico (geschichtlichen Mensch) en su llegar a ser en casa (Heimischwerdens). El río es la localidad (Ortschaft) para el lugar del hogar (heimischen Ortes). El río determina al mismo tiempo el futuro encontrarse en casa (Werden des Heimischseins) de los seres humanos históricos. El río es la travesía (Wanderschaft) de este trayecto (Wanderung) en el cual el futuro encontrarse en casa tiene su esencia. El río es ambos, y lo es en originaria unidad (ursprünglichen Einheit). El ser humano histórico está cimentado con relación a esta esencia del río» (Heidegger, 1984: 51). 
Anfang nicht an der Quell. Ihn zehret die Heimath» ${ }^{3}$. La dificultad, es decir, que el «espíritu» no se encuentre en casa ni en el inicio ni en la fuente, es acentuada por Heidegger mediante la distinción entre «inicio» (Anfang) y "comienzo» (Beginn), algo que despunta en los textos que orbitan en torno a Beiträge zur Philosophie, especialmente en Über den Anfang, y que inaugura sus cursos sobre Hölderlin: "“comienzo" (Beginn) es algo distinto a "inicio" (Anfang)» (Heidegger, 1999: 3). De este modo, afirma Heidegger que en el anterior verso de Hölderlin «inicio (Anfang) nombra el comienzo (Beginn). Así, inicio quiere decir otra cosa que fuente» (Heidegger, 1984: 161), pudiendo Heidegger radicalizar esta distinción años más tarde hasta afirmar que «el inicio (Anfang) se oculta en el comienzo (Beginn)» (Heidegger, 2002: 156). El comienzo (Beginn), de este modo, tal y como lo presenta Heidegger, se pierde en aquello en él o por él comenzado, se disuelve y olvida en su comenzar, mientras que el inicio (Anfang) se encuentra presente incluso cuando aquello iniciado ha llegado a su acabamiento, incluso cuando el río ha ido a desembocar al mar. De este modo, si bien el inicio (Anfang) debe haberse iniciado, es decir, debe en cierta forma haber "comenzado", no por ello se adentra en la oscuridad de la ausencia o de la pérdida: «es verdad que lo inicial (das Anfängliche) es algo sido (Gewesenes) pero no pasado (Vergangenes). Lo pasado es siempre lo ya-no-ente (Nicht-mehr-Seiende), mientras que lo sido es el ser todavía esenciante (nochwesende Sein); el ser es, a su vez, lo oculto en su inicialidad (Anfänglichkeit Verborgene)» (Heidegger, 1991: 86).

El inicio (Anfang) se encuentra presente, permanece (bleiben) y, sin embargo, en cuanto tierra natal (Heimat), en cuanto fuente (Quelle), es lo más distante, lo más inalcanzable: esto corresponde a lo que Heidegger denomina «misterio» (Geheimnis) (Heidegger, 1981, 24), el encontrarse en casa sin estar en casa (Heimisch-Unheimischsein), el estar en casa en cuanto travesía (Wanderschaft), es decir, en cuanto encaminarse a casa (Heimischwerden): el hogar, lo propio, por tanto, no es sino el trayecto a casa y nada más. Así, señala Heidegger, del mismo modo que los griegos, cuya tierra natal era el «fuego del cielo», sólo pudieron «apropiarse» de su inicio desde lo más extraño (Fremde), desde la «claridad de la exposición» (Heidegger, 1981: 87), los hombres y el río Ister se aventuran en el «valiente olvido» (tapfer Vergessen) que deja atrás su inicio para recuperarlo en su propiedad a través del exilio, de la enajenación y de la travesía (Cfr. Heidegger, 1984: 172-173). Que la identidad de lo propio sólo se realiza a través de la

3 «En efecto, en casa no está el espíritu / al inicio, no está en la fuente. La tierra natal lo consume». 
experiencia interminable de la alteridad es, por otra parte, algo en lo que insiste Derrida ya desde sus primeros textos. Siendo la huella en cuanto no-presencia del otro o de lo otro aquello que constituye el instante "presente»" ${ }^{4}$, la propiedad de lo propio sólo puede ser comprendida desde la necesaria y anterior relación con la radical alteridad, con un otro que me constituye antes de que "yo" sea "yo mismo" 5 . De este modo, volviendo a Heidegger, éste equipara lo sido (Gewesene) con el por-venir ( $Z u$-kunft) o lo venidero (Kommende) y lo diferencia del mero pasado (Vergangenen), afirmando que «bien está pensar en lo ya sido (Denken an das Gewesene), pero ahora lo que importa también, como si de un único y mismo pensar se tratara, es hacer memoria y pensar en lo venidero (An-denken an das Kommende)» (Heidegger, 1981: 117).

El origen, por tanto, lo original u originario, se deja perder, se extravía para sólo así recuperarse en cuanto "verdadero» origen, dando paso al «otro inicio» (anderen Anfang) desde el «primer inicio» (ersten Anfang) ${ }^{6}$. Esta apropiación del origen propio supone que, en su repetición, en su readquisición, lo que se obtiene verdaderamente desde esa sombra que viene es un «nuevo» origen, es decir, que el pasado, en su repetición, se constituye desde y como porvenir ${ }^{7}$, algo que

4 Esto es, por lo demás, algo que Derrida seńala ya al comienzo de De la grammatologie: «la huella, donde se marca la relación con lo otro, articula su posibilidad sobre todo el campo del ente, que la metafísica ha determinado como ente-presente a partir del movimiento ocultado de la huella. Es necesario pensar la huella antes que el ente. Pero el movimiento de la huella está necesariamente ocultado, se produce como ocultación de sí. Cuando lo otro se anuncia como tal, se presenta en la disimulación de sí [...] El campo del ente, antes de ser determinado como un campo de presencia, se estructura según las diversas posibilidades -genéticas y estructurales- de la huella. La presentación de lo otro como tal, es decir, la disimulación de su "como tal", ha comenzado desde un principio y ninguna estructura del ente le escapa» (Derrida, 1967: 69).

5 Como seńala Derrida, «el cierre no es más que una reacción a una primera apertura. Desde este punto de vista, la hospitalidad es primera. Decir que es primera significa que incluso antes de ser yo mismo y quien yo soy, ipse, es preciso que la irrupción del otro haya instaurado esa relación conmigo mismo. Dicho de otro modo, no puedo tener relación conmigo mismo, con mi "estar en casa" más que en la medida en que la irrupción del otro ha precedido a mi propia ipseidad» (Derrida, 1999a: 51).

6 La relación entre el primer inicio y el otro inicio no es de superación, si por tal entendemos comprender sus «causas» o «motivos». Como señala Heidegger, «nunca rige en el recuerdo (Erinnerung) del primer inicio (ersten Anfang) regresar "detrás" de éste, sino avanzar desde su intimidad (Innigkeit) al otro comienzo (anderen Anfang)» (Heidegger, 2005: 91).

7 Es quizá en este sentido en el que Heidegger señala que debe pensarse más griegamente que los griegos para, en esta repetición del origen del pensamiento, dar lugar a un nuevo comienzo sin que ello suponga una «mejor» comprensión de lo que los griegos mismos «quisieron decir» (Cfr. Heidegger, 1985: 127). 
Derrida señala bajo el término «iterabilidad», es decir, «el surgimiento de lo otro (itara) en la reiteración» (Derrida, 2001: 367). Por otra parte, esta idea del pasado en cuanto porvenir la planteaba Heidegger ya en Sein und Zeit, donde se afirma que el mundo del Dasein resuelto debe ser reiterado (Wiederholung) a través del retorno (Wiederkehr) a él y no simplemente restaurado (Wiederbringen), es decir, re-presentado, suponiendo este retorno (Wiederkehr), por tanto, "un regreso fecundo al pasado en el sentido de una creadora apropiación de él» (positiven Rückgang zur Vergangenheit im Sinne einer produktiven Aneignung ihrer) (Heidegger, 1977a: 29). De este modo, como seńala Heidegger, solidaria de la distinción entre «inicio» (Anfang) y «comienzo» (Beginn) habría que situar la de «historia» (Geschichte) e "historiografía» (Historie). La historiografía (o historia impropia) comprendería su objeto de estudio como la disponibilidad en el pasado (Vergangenen), es decir, como un comienzo (Beginn) cuyas causas afectarían, de un modo u otro, al momento presente, mientras que la historia (Geschichte), es decir, la «historia acontecida», consistiría en la destinación en cuanto esenciarse de la verdad del ser ${ }^{8}$. Ahora bien, en cuanto este «origen» del inicio (Anfang) sólo es tal en y desde la alteridad que como repetición lo inaugura (pues, como señala Derrida, «en el origen [origen sin origen, pues] no hay nada simple, sino una composición, una contaminación, la posibilidad al menos de un injerto y de una repetición» [Derrida, 2001:370]), ello equivale a decir que este «origen», el origen mismo de lo propio, no ha sido nunca, propiamente, tal: es un origen sin pasado, un no-origen, la borradura del origen (Cfr. Derrida, 1967: 90).

Así, el origen se nos da, se nos encomienda y nos pide ser apropiado, siendo esta apropiación, efectivamente, su origen, su inauguración: como señala Derrida siguiendo la (a)lógica de la iterabilidad anteriormente seńalada, la repetición como inauguración presenta el cortocircuito entre lo constatativo y lo performativo (Cfr. Derrida, 1987a: 35), es decir, que la repetición de lo que no ha sido propiamente nunca supone su invención. De este modo, dado que el origen o

8 Esta distinción es tratada extensamente por Heidegger ya desde Sein und Zeit, por lo que recoger aquí su profundidad queda lejos de la capacidad de este estudio, Remito, de este modo, al esclarecedor texto de François Jaran (Cfr. Jaran, 2010). No obstante, como mero apunte, Heidegger seńala que «la historia acontecida del ser es el destino del ser, que se nos asigna y destina en tanto que retira su esencia (Seinsgeschichte ist das Geschick des Seins, das sich uns zuschickt, indem es sein Wesen entzieht)" (Heidegger, 1997: 90), por lo que "la historia acontecida del ser no es ningún proceso objetualmente representable y sobre el cual pudieran narrarse la "Historia del ser"» (Heidegger, 1997: 139). Así, "“lo historiográfico" es lo comprobado (Festgestellte), comprobable y explicado. "Lo histórico" no es comprobable; y ello no porque el conocimiento fuera insuficiente, sino porque no es en sí algo comprobable, un ente, sino el Seyn» (Heidegger, 2005: 180). 
lo original se entrega y así se inaugura, se origina, afirma Derrida que «el original se da modificándose, su don no es un objeto dado, él vive y sobrevive en mutación» (Derrida, 1987a: 217). Ahora bien, si esto original que se nos da en cuanto origen no es nada, nada "presente», nada "pasado", sino "puro" por-venir o estar-viniendo sin terminar de "llegar», este pensamiento del don es, como señala Derrida, un pensamiento «loco», un pensamiento en torno a la locura; un pensamiento, en definitiva, sobre lo que no se deja pensar (Cfr. Derrida, 1991: 52-53). Porque este origen que no es se da, es decir, da lo que no tiene, rompiendo así el binomio entre el dar y el tener en una economía general que no consiste en que alguien da, intercambia o entrega «algo» a alguien que quedaría por ello en deuda, tal y como sucede en la economía restringida: si se entrega, el don se anula, por lo que aquello que se entrega no debe aparecer, no debe devenir un presente (présent) sino que deber permanecer como secreto?.

Aquello que se da como origen para ser apropiado es, verdaderamente, la incineración misma del origen, su erradicación, su holocausto que da un resto, casi nada, una sombra o una ceniza ${ }^{10}$ que debe ser leída, que debe ser asumida e inventada. El origen, esa nada que viene, es la ruina misma, la ruina como origen: «en el origen llega la ruina, ella es lo que llega primero, el comienzo» (Derrida, 1990: 69) sin ser, no obstante, «ruina de». Con lo que nos encontramos, por tanto, el origen, es casi nada: "nos aguarda la ceniza» (Derrida, 1986: 40) que no puede ser apropiada; que, como señala Derrida, no puede ser recuperada mediante un proceso hermenéutico (Cfr. Derrida, 2004a: 536) en el que se restauraría su querer-decir originario, su primera palabra, su auténtica palabra. Las cenizas (pues estas son siempre en plural) no pueden reconstituirse

9 Derrida plantea de este modo la imposibilidad del don y la necesidad de su no aparición: «para no hacer mella en el otro, la sorpresa del don puro debería tener la generosidad de no dar nada que sorprenda o que aparezca como don, nada que se presente como presente, nada que sea; la sorpresa debería, por lo tanto, ser bastante sorprendente y estar, de arriba abajo, hecha de una sorpresa que ni siquiera se plantea estar de vuelta, por consiguiente, de una sorpresa lo bastante sorprendente como para hacerse olvidar sin dilación. Y puesto que este olvido va más allá de cualquier presente, de lo que se trata es del don como restancia sin memoria, sin permanencia y sin consistencia, sin sustancia ni subsistencia; de lo que se trata es de ese resto que es, sin ser(lo), más allá del ser, epekeina tes ousias. El secreto de aquello de lo que no se puede hablar, pero que no se puede callar» (Derrida, 1991: 187).

10 Así lo señala Derrida en Glas: «el proceso del don (antes del intercambio), proceso que no es un proceso sino un holocausto, un holocausto del holocausto, empeña (engage) la historia del ser pero no le pertenece. El don no es, el holocausto no es, al menos si los hay (il y en a). Pero en cuanto (que) quema (el incendio no es un ente) debe, quemándose a sí mismo, quemar su operación de quemar y comenzar a ser» (Derrida, 1974: 270A). 
o recomponerse en su cuerpo originario, como si de un Fénix se tratase. De este modo, el don del origen (si lo hay) se da y se borra como tarea del porvenir en cuanto ceniza, en cuanto resto originario ${ }^{11}$, dando así, precisamente, el tiempo al porvenir, lo que Heidegger puede llamar «destinar» (Schicken) ${ }^{12}$. Y es Derrida quien, aproximando este pensamiento del don como ruina o ceniza a Heidegger, señala que el término «Ereignis», "que normalmente significa el acontecimiento, hace guińos hacia un pensamiento de la apropiación o de la desapropiación que no puede carecer de relación con el pensamiento del don» (Derrida, 1991: 33). Si el don del origen es la ruina del ser, se comprende que Derrida pueda afirmar, parodiando a Heidegger, «la ceniza como la casa del ser» (Derrida, 1987b: 25), es decir, que la ceniza misma en cuanto darse lo que es propiamente nada pone en marcha el «efecto de restancia» de la huella, movimiento que no puede detenerse y que se constituye como "origen» inapropiable ${ }^{13}$. El origen en cuanto tierra natal (Heimat) es, por tanto, la pérdida de lo propio, lo propio como pérdida, siendo así la donación (Verschenkung) el rechazo (Verweigerung) de la donación como

11 La ceniza, como señala Derrida, se encontraría «antes» del ser mismo en cuanto darse del ser: "entiendo que la ceniza no es nada que esté en el mundo, nada que reste (reste) como un ente. Es el ser, más bien, que hay -es un nombre del ser que hay ahí pero que, al darse (es gibt ashes), no es nada, resto (reste) más allá de todo lo que es (konis epekeina tes ousias), resto (reste) impronunciable para hacer posible el decir a pesar de que no es nada» (Derrida, 1987b: 57).

12 «A un dar que se limita a dar su don, su dádiva, y que, sin embargo, se reserva a sí mismo y se retira, a un tal dar lo llamamos el destinar (Ein Geben, das nur seine Gabe gibt, sich selbst jedoch dabei zurückhält und entzieht, ein solches Geben nennen wir das Schikken). Conforme al sentido que así hay que pensar de dar, es el ser, que se da, lo destinado (Geschickte). De esta manera destinada queda cada una de sus transformaciones» (Heidegger, 2007: 12).

13 Aun siendo una nota algo extensa, Derrida describe perfectamente la relación entre la huella, la ceniza, el efecto de restancia y el origen de este modo: «una huella nunca está presente, plenamente, plenamente presente, por definición, inscribe en sí la remitencia al espectro de otra cosa. El resto tampoco está presente, como tampoco una huella como tal. Y por esto la cuestión del resto me ha ocupado mucho, con frecuencia bajo este mismo nombre o más rigurosamente bajo el de restancia. La restancia del resto no se reduce a un residuo presente ni siquiera a lo que permanece después de una sustracción. El resto no es, no es un ente, una modificación de lo que es. Como la huella, la restancia se da a pensar antes o más allá del ser. Inaccesible a una simple percepción intuitiva (ya que remite a lo radicalmente otro, inscribe en sí lo infinitamente otro), escapa a toda aprehensión, a toda monumentalización, incluso a toda archivación. Con frecuencia, como la huella, la asocio a la ceniza: resto sin resto sustancial, en suma, pero con el que hay que contar y sin el que no habría ni cuenta ni cálculo, ni principio de razón que viniera a dar cuenta o razón, ni ente como tal. Por esto hay efecto de resto, en el sentido de resultado o de residuo presente, idealizable, idealmente iterable. (...) Dispersión de los efectos de resto, interpretaciones diferentes, pero en ningún lugar la sustancia de un resto presente e idéntico a sí» (Derrida, 2001: 385). 
origen. Así, relacionando la donación del inicio con el ocultamiento o pérdida dadivosa que permanece como tal huida, señala Heidegger:

El "permanecer" (Bleiben) apropiado al inicio (Anfang eignet) no es persistir (Andauern), sino el aislamiento como ocaso en el encubrimiento (die Abgeschiedenheit als Untergang in die Verbergung). Por ello es cada vez el inicio (Anfang) desde el aislamiento un abismo de la donación (Abgrund der Verschenkung), porque todavía dona la garantía de la esencia de una donación (Gewähr des Wesens einer Schenkung verschenkt), que sin la nada nunca podría transferir. (Heidegger, 2005: 15).

De este modo, el inicio (Anfang) se da como comienzo (Beginn) y así se oculta en la mayor lejanía que, simultáneamente, supone la mayor donación de sí ${ }^{14}$. Este ocultamiento u ocaso no implica, en modo alguno, el cese (Aufhören) o el fin (Ende) del inicio, sino que «el ausentarse (Ausbleiben) es el permanecer desde la despedida (Bleiben aus dem Abschied). Esta ausentarse no es ningún cesar, sino que es el íntimo esenciar del iniciar en ocaso (innige Wesen des untergänglichen Anfangs)» (Heidegger, 2005: 38). De este modo, cuando Heidegger plantea el pasado como sombra (Schatten) no lo hace en cuanto sombra de una presencia "originaria», de algo que se encontraría «detrás» y que por tanto podría ser reincorporado en una «Erinnerung», sino que la sombra como casi nada es el ser mismo y nada más: «el ser y la nada no se dan el uno junto al otro; el uno se emplea en el otro y para el otro» (Heidegger, 1975: 419). El ser, como nada, es el espectro. Por tanto, puesto que «aquellos que han sido" nos visitan por primera vez siempre de nuevo como sombras, no podemos sencillamente darles la forma que les habría sido propia antes de devenir esa sombra que son, es decir, reconstituir su cuerpo propio. De este modo, escuchar (hören) a las sombras que se nos dan es, efectivamente, volver a decir (omo-logein) (Heidegger, 2000: 225-226) aquello que han sido y, por tanto, hacer memoria de una forma tal que jamás se alcanza lo que hay tras o anterior a su borradura: «el hombre es en su esencia la memoria del ser (Gedächtnis des Seins), pero del ser» (Heidegger, 1975: 411). Hacer memoria de las sombras es encaminarse hacia ellas sin llegar a alcanzarlas

14 También en Über den Anfang señala Heidegger: «La esencia del Seyn es el inicio (Anfang). El iniciar del inicio es la despedida (die Anfängnis des Anfangs ist der Abschied). El iniciar es el Ereignis del ocaso (Untergang). El ocaso es la intimidad del iniciar. La despedida es la lejana llegada (Ankunft) del encubrimiento (Vergegens) del depósito (Verwahrung) del curso (Fortgang) en el inicio. La despedida es llegada, no en el presenciarse (Anwesung) de un presente a la mano, sino llegada inicial, que retrocede ante sí y se detiene en su más lejana lejanía» (Heidegger, 2005: 24). 
nunca, sin poder disponer de su retirada ${ }^{15}$. Estas sombras, por tanto, se corresponden con lo que Derrida comprende por «espectro", aquello que nos asedia, que comienza por retornar, cuya "primera vez» es ya siempre «haber sido», esto es, un pasado conjugado siempre en futuro anterior (Cfr. Derrida, 1986: 48). Porque, como sucede en Heidegger, este pasado presentado como porvenir que es el espectro supone el límite, la encrucijada entre la presencia y la no-presencia, entre el ser y la nada (Cfr. Derrida, 1993b: 25-26), entre el estar y el venir: tal y como apunta Aragón González, «si la huella ni está presente ni ausente, otro tanto habría que decir del espectro: ni vivo ni muerto, sobreviene, sobrevive. No podemos decir que sea ni que no sea. Viene pero no llega» (Aragón, 2011: 299). En definitiva, si el movimiento del espectro es el de la venida sin llegada ello se debe fundamentalmente a que carece por completo de destino, de una dirección definida, sea de ida o de vuelta, encontrándose de este modo en lo que Derrida denomina «destinerrancia»y, por tanto, en la permanente constitución de sí en su repetición im-posible.

El espectro, por tanto, se encuentra ahí, allí, viniendo y observándonos sin poder llegar a ser visto. Porque los espectros, como señala Derrida, se nos dan, se nos encomiendan y nos asedian sin que nunca podamos identificar su rostro, sin que podamos determinar a quién corresponde esa sombra en lo que Derrida denomina «efecto visera» (Cfr. Derrida, 1993b: 26). Este espectro, por tanto, no se deja reincorporar en una imagen, no se deja recordar en una "Erinnerung", no permite que sus restos se «ontologicen» y sean convertidos en «restos de» algo o alguien. De este modo, en la medida en que el espectro no dispone de una tumba no puede aquietarse y ser digerido en el duelo melancólico, sino que, por el contrario, se ve obligado a vagar, a darse cada vez, a perderse, a no llegar nunca a su definición: como señala Derrida, se trata de «llevar permanentemente el luto por lo que nunca se tuvo» (Derrida, 1996a: 61). Qué sea este espectro, estas sombras, en definitiva, es un secreto. Ahora bien, así como la sombra no resultaba ser sombra-de, es decir, que en cuanto origen carecía de «original», el secreto no consiste tampoco en la ocultación de un mensaje, de un contenido al que bastaría con retirar los velos para contemplar en su propiedad, para identificar en su «querer-decir». El secreto, como señala Derrida, se encuentra más allá del binomio ocultación-desocultación, presencia-ausencia, desvelado-velado,

15 Señala Heidegger a este respecto: «el hombre es un signo (Zeichen) en el camino hacia lo que se sustrae (Zug in das Sichentziehende). Pero como este signo indica lo que se sustrae en cuanto se escapa, no señala tanto lo que allí se sustrae, como el sustraerse. El signo queda sin interpretación (Deutung)» (Heidegger, 2002: 11). 
siendo por tanto posible afirmar que este secreto, aun cuando sea «manifestado», no por ello resulta menos secreto (Cfr. Derrida, 1993a: 60).

En este sentido, si las sombras del pasado a las que escuchamos y a las que intentamos dar una respuesta permanecen siempre en secreto y por tanto no podemos acercarnos a lo que en su propiedad son, no queda más opción que la continua aproximación a esa incesante venida de lo sido en lo que Derrida denomina movimiento catastrópico o catacresis (Cfr. Derrida 1987a: 81-82). Así, puesto que las sombras no dicen «nada» que pueda ser identificado como su palabra, escuchar aquello que nos dicen es, como señala Heidegger, una «transducción» (Übersetzen), es decir, una traducción (Übersetzen) que no consiste en el mero transporte (Übertragung) de la palabra del espectro a mi lengua mediante el uso de un diccionario bilingüe que imitaría y reproduciría su significado dado (Bedeutung), sino que más bien la transducción consiste en el salto que nos acercaría a lo por él dicho en cuanto por-pensar ${ }^{16}$, es decir, al abismo (Graben) mismo en cuanto secreto (Cfr. Heidegger, 2002: 236; Heidegger, 1977b: 245). Así, mediante esta transducción (Übersetzen) el secreto del espectro no es desvelado, sino interpretado: como señala Heidegger, «todo traducir debe ser una interpretación (Auslegung). Y lo mismo a la inversa: toda interpretación es traducir» (Heidegger, 1984: 75) y, por tanto, la necesaria «transformación» en cuanto invención de lo recibido (Cfr. Derrida, 1972: 31).

Ahora bien, Derrida señala que, quizá, pueda encontrarse en Heidegger cierta tendencia melancólica que intentaría reapropiarse del único y auténtico nombre del espectro, del nombre del ser y, por tanto, continuaría comprendiendo su secreto como aquello que es susceptible de ser desvelado y resuelto (Cfr. Derrida, 2012: 10-11). Sin embargo, Heidegger insiste en señalar que escuchar la palabra del ser no es comprenderla si por tal entendemos identificar y apresar un contenido semántico, esto es, traducirla en sentido clásico sino, por el contrario, arrojarse a una interpretación (Auslegung) por medio de la transducción que se encamina hacia el lugar del esenciarse del ser en cuanto verdad del ser, es decir, en cuanto donación en aclarante-ocultación. Porque, como afirma Heidegger,

\footnotetext{
16 De este modo, afirma Heidegger: «pensar es pensar por anticipado que piensa-en, que conmemora (Denken ist andenkendes Vordenken); ni se adhiere -historiográficamente, y de manera representativa- a lo sido (Gewesenen), como si éste fuera cosa pasada (Vergangenen), ni se rigidifica representándolo, con profética desmesura, en un futuro presuntamente sabido. El pensar que piensa-en y que piensa-antes-de es el acto de saltar propio del salto (Das andenkend-vordenkende Denken ist das Springen des Sprunges). Este salto es una trans-posición (Satz), a la cual se ajusta (fügt) el pensar» (Heidegger, 1997: 140).
} 
todo lo que se muestra lo hace en el camino: el camino es el mostrarse mismo ${ }^{17}$. Por tanto, si bien es cierto que Heidegger insiste en la capitalidad de «la Palabra» (das Wort) que se correspondería con la apertura misma de toda palabra (Aufriss), esta "palabra» no es tal más que en los ecos y «trazos» (Riss) en los cuales resuena y se inscribe, siendo por tanto absolutamente impronunciada e impronunciable, irremontable (Cfr. Heidegger, 1985: 254). De este modo, Heidegger no comprendería que escuchar (hören) la palabra de esas sombras que está viniendo consista en apropiársela de una forma definitiva, clausurante y perfecta sino, por el contrario, en el encaminarse ilimitadamente hacia aquello que en la palabra resta y llama a lo por-pensar, hacia aquello que en la palabra constituye el guiñar (winken) del espectro. Escuchar (hören) es por tanto pertenecer (gehören) a la palabara (das Wort) dada y llevarla al habla (die Sprache als die Sprache zur Sprache bringen) en palabras (Heidegger, 1985: 228-236).

El espectro, el origen o lo original, necesita ser transducido o transformado, es decir, recibido e interpretado. Como señala Derrida, el «original», que es sin origen, requiere «a priori» la traducción ${ }^{18} \mathrm{y}$, por tanto, el proceso de lecturas infinitas que leen lo ilegible en cuanto ilegible. Ahora bien, puesto que esta nada que es el espectro en su darse no puede ser apropiada "como tal» sino que verdaderamente reclama su repetición en cuanto invención, la escucha de su palabra, su recepción, se inscribe en lo que Derrida denomina «herencia». En este sentido, Derrida señala que:

$[\mathrm{H}]$ eredar no es en esencia recibir algo, un elemento dado que entonces se puede tener. Es una afirmación activa, responde a una conminación pero supone también la iniciativa, la firma o la refrendación de una selección crítica. Cuando se hereda, se clasifica, se criba, se valora, se reactiva (Derrida, 1996c: 33).

17 «Todo aquello que hay que avistar (erblicken) se muestra siempre y en todo caso en el camino, de camino. Todo lo que hay que avistar está en manos del camino. Dentro del campo visual abierto por el camino y por el que él conduce, se reúne (sammelt) lo en cada caso avistable en virtud del camino" (Heidegger, 1997: 88).

18 La necesidad de la traducción por parte del original la señala Derrida de este modo: «el original no es algo pleno que de forma casual recibe una traducción. La situación del original es la situación de solicitud, es decir, de una falta, de un exilio: el original está a priori en deuda con la traducción. Su supervivencia es una exigencia de traducción, un deseo de traducción, de una manera parecida a la exigencia de Babel: "tradúceme"» (Derrida, 1982: 172). 
Puesto que aquello que se hereda es propiamente «nada», el secreto, la inyunción que nos reta a leerla, la conminación no es en modo alguno un mero almacenamiento, sino el porvenir en cuanto responsabilidad ${ }^{19}$. En este sentido, el heredero es infinitamente responsable de la herencia, del espectro que recibe $\mathrm{y}$ al que le da una forma que nunca llegará a corresponderse con una identidad definitiva. El espectro no es nunca uno sino siempre «sombras», multitud del espectro sobre el que se tiene que elegir, al que se tiene que cribar en una hospitalidad restringida que siempre mira hacia la hospitalidad absoluta en cuanto justicia ${ }^{20}$. De este modo, como afirma Derrida, la herencia de las sombras, su «ser» en cuanto «darse» no puede nunca aquietarse en "la» herencia: siempre son plurales, siempre son "herencias» ${ }^{21}$ de los espectros. De este modo, puesto que la alteridad del espectro en cuanto no-ser que se da es absoluta, la memoria que de él se haga siempre será culpable, es decir, nunca podrá estar a la altura de aquello que le ha sido encomendado a la memoria ${ }^{22}$. Por ello, si bien Heidegger

19 La herencia y la responsabilidad son sinónimos absolutos para Derrida: «que seamos íntegramente herederos no significa que el pasado nos dicte cualquier cosa. Hay, es cierto, una conminación que viene de él. No hay conminación que no venga de un cierto pasado como por venir. Pero esta conminación nos intima a responder ahora, a elegir, seleccionar, criticar. Yo disociaría entonces el concepto de herencia de los de patrimonio, banco, almacenamiento» (Derrida, 1996: 80).

20 Como señala Derrida, «entre una ley incondicional o un deseo absoluto de hospitalidad por una parte y, por otra parte, un derecho, una política, una ética condicionales, existe diferencia, heterogeneidad, pero también indisociabilidad. Una implica o prescribe a la otra» (Derrida, 1997: 131).

21 «Una herencia nunca se re-úne, no es nunca consigo misma. Su presunta unidad, si existe, sólo puede consistir en la inyunción de reafirmar eligiendo. Es preciso quiere decir es preciso filtrar, cribar, criticar, hay que escoger entre los varios posibles que habitan la misma inyunción. Y habitan contradictoriamente en torno a un secreto. Si la legibilidad de un legado fuera dada, natural, transparente, unívoca, si no apelara y al mismo tiempo desafiara a la interpretación, aquél nunca podría ser heredado. Se estaría afectado por él como por una causa -natural o genética-. Se hereda siempre de un secreto -que dice: "Léeme. ¿Serás capaz de ello?"» (Derrida, 1993b: 40).

22 En este sentido, en cuanto la memoria es infinitamente responsable de lo que no puede llevar a cabo es también infinitamente culpable: «soy responsable ante el otro en cuanto que otro, le respondo y respondo ante él. Pero, por supuesto, lo que me vincula así, en mi singularidad, con la singularidad absoluta del otro me arroja inmediatamente al espacio o al riesgo del sacrificio absoluto. Hay también otros en número infinito, la generalidad innumerable de los otros, con los cuales me debería vincular la misma responsabilidad, una responsabilidad general y universal (lo que Kierkegaard llama el orden ético). No puedo responder a la llamada, a la petición, a la obligación, ni siquiera al amor de otro, sin sacrificarle otro otro, otros otros. Cualquier/radicalmente otro es cualquier/radicalmente otro (...) Y jamás podré justificar este sacrificio, deberé siempre callarme al respecto. Lo quiera o no, nunca podré justificar que prefiero o que sacrifico el uno (un otro) al otro» (Derrida, 1999b: 97-98 y 101). 
señala que la tarea del pensamiento (Denken), en cuanto memoria (Andenken) tiene que ser un agradecer (Danken) aquel don en el que la sombra se nos entrega como por-pensar, Derrida afirma que, efectivamente, siempre se comienza, en la herencia de las sombras, por dar las gracias (merci) pero, dado que esta recepción nunca satisfará la petición infinita de las sombras en cuanto espectro, dado que debe haber una contra-firma, un dar-y-tomar y una negociación infinita entre la justicia y el derecho, esta primera palabra, este primer «sí» que da gracias deviene inmediatamente la petición de perdón, de misericordia (mercy) por no haber podido ser justo con el espectro. Así, señala Derrida, se da las gracias y al mismo tiempo se pide misericordia por (pour) ser justo, es decir, por haber sido capaz de recibir la herencia de «este» espectro pero, por otra parte, se pide perdón para (pour) ser justo con el interminable porvenir del otro, del espectro, de las sombras. De este modo, si bien Heidegger establece claramente en sus últimos textos la primacía del «decir confiador» (Zusage ${ }^{23}$, Derrida señala que esta "primera» palabra nunca puede ser única, un mero «sí»: «al comienzo habría la palabra "perdón", "gracia(s)"” (Derrida, 2004b: 559).

Puesto que la primera palabra del espectro es ya la división, la guerra o el guerrear (il guerre), el espectro y sus sombras son no una utopía o, como diría Heidegger, "algo que no tiene lugar (etwas, was keinen Ort hat)» (Heidegger, 1982: 141), sino la aporía, lo irresoluble mismo. El espectro es desde el origen más de uno, un abrirse o una apertura, un espaciamiento. Ahora bien, es precisamente en este último momento del acercamiento al espectro, en este haberlo dicho casi todo, esto es, casi nada, cuando las sombras de Heidegger y Derrida toman mayor distancia. En su texto Apories señala Derrida la insistencia heideggeriana en afirmar la imposibilidad (Unmöglichkeit) como lo más propio del Dasein y precisamente como aquello que se debe mostrar, como aquello que debe afirmarse en cuanto imposible: en ello consistiría propiamente la posibilidad de lo imposible (die Möglichkeit der Unmöglichkeit), es decir, en la vivencia del fracaso (Scheitern) como tal. El espectro, por tanto, debería manifestarse como la imposibilidad misma, como lo más imposible. De este modo, para Derrida, Heidegger comprende que la imposibilidad, la aporía que es el espectro «mismo» debe aparecer o recibirse como imposible, es decir, en cuanto la aporía como tal. Ahora bien, ya se citó anteriormente el fragmento de De la grammatologie

23 «Toda pregunta (Anfragen) acerca del asunto del pensamiento (Sache des Denkens), todo inquirir (Nachfragen) acerca de su esencia, está llevado ya por el decir confiador (Zusage) de lo que viene en cuestión. El verdadero gesto del pensamiento ahora necesario es la escucha del decir confiador y no el preguntar» (Heidegger, 1985: 169). 
donde Derrida seńala que "cuando lo otro se anuncia como tal, se presenta en la disimulación de sí»: una aporía, por ser y para ser tal, nunca puede mostrarse y recibirse como tal, nunca puede venir a presencia (Anwesenheit) (Cfr. Derrida, 1993b: 52-54). De este modo, el espectro no es nunca el espectro, por más que éste se comprenda como espeetro, sino que la aporía del espectro como tal es el abismo del como tal ${ }^{4}$, aquello que no puede tener ni tan siquiera ese mínimo de propiedad. Tomando distancia de Heidegger, afirma Derrida que no se trata de la utopía del espectro, de lo que no tiene lugar propio y que debe experimentarse como tal, dándole así un cierto lugar y haciéndolo algo más asimilable, sino que el espectro es lo «im-posible», aquello que no es lo más posible en cuanto no-posible, sino lo imposible que da el tiempo de o a lo posible. En este sentido, efectivamente, Heidegger comprendería la imposibilidad del espectro desde la «Versammlung», desde la reunión que debe ser nombrada (Nennen) en cuanto Claro (Lichtung) y por tanto en el juego del venir a la presencia de lo impresentable, en el «llevar-a-mostrarse» (zum-sich-zeigen-bringen) la retirada misma.

El espectro, por tanto, en cuanto darse o don que es el ser, es pensado tanto por Heidegger como por Derrida como lo imposible, como la aporía. Sin embargo, es precisamente en este último momento que se aproxima hacia la imposibilidad del espectro cuando las sombras que para nosotros son Heidegger y Derrida resultan imposibles de identificar, imposibles de conjugar. En su decir lo mismo, en su decir el espectro, se constituye entre Heidegger y Derrida una distancia infinita, un paso (pas). Ahora bien, es quizás este encuentro que no tiene lugar la única exposición posible del pensamiento en torno a la espectralidad en Heidegger y Derrida: el dejar como tarea, como herencia, la imposibilidad de su relación, el espectro y las sombras de una intimidad que no tiene identidad. Pero esto abre precisamente la responsabilidad de la lectura, el deber de convertirnos en los inventores del pasado, de la relación entre Heidegger y Derrida. Como espectros que son, por tanto, tan sólo se les puede agradecer su don y pedirles perdón por la injusticia de esta lectura.

\footnotetext{
24 También podría decirse que el «como tal» del espectro es, precisamente, su sin «como tal»: «si hay que resistir la aporía, si ésta es la ley de todas las decisiones, de todas las responsabilidades, de todos los deberes sin deber para todos los problemas de frontera que puedan presentarse alguna vez, no se puede simplemente resistir la aporía como tal. La aporía última es la imposibilidad de la aporía como tal» (Derrida, 1996b: 136-137).
} 


\section{Bibliografía}

Aragón González, L. (20 I I) "El testimonio y sus aporías” en: Escritura e imagen. n. ext. pp. 295-311.

Derrida, J. (1967). De la gramatologie, Paris: Les Éditions de Minuit.

Derrida, J. (1972). Positions, Paris: Les Éditions de Minuit.

Derrida, J. (1974). Glas, Paris: Galilée.

Derrida, J. (1982). L'oreille de l'autre. Otobiographies, transferts, traductions, Montréal: VLB Éditeur.

Derrida, J. (1986). Schibboleth. Pour Paul Celan, Paris: Galilée.

Derrida, J. (1987a). Psyché. Inventions de l'autre, Paris: Galilée.

Derrida, J. (1987b). Feu la cendre, Paris, Éd. des femmes.

Derrida, J. (1990). Mémoires d'aveugle, Paris: Éditions de la Réunion des Musées Nationaux.

Derrida, J. (1991). Donner le temps. 1. La fausse monnaie, Paris: Galilée.

Derrida, J. (1993a). Passions, Paris: Galilée.

Derrida, J. (1993b). Spectres de Marx, Paris: Galilée.

Derrida, J. (1996a). Le monolinguisme de l'autre, Paris: Galilée.

Derrida, J. (1996b). Apories. Mourir-s’attendre aux "limites de la vérité", Paris: Galilée.

Derrida, J. (1996c). Échographies de la télévision. Entretiens filmés, Paris, Galilée.

Derrida, J. (1997). De l'hospitalité, Paris: Calmann-Lévy.

Derrida, J. (1999a). Sur Parole. Instantanés philosophiques, Paris: Éditions de l'Aube.

Derrida, J. (1999b). Donner la mort, Paris, Galilée.

Derrida, J. (2001). Papier Machine, Paris, Galilée. 
Derrida, J. (2004a). "Poétique et politique du témoignage". En: Mallet, MarieLouise; Michaud, Ginette (éds). Cabier de l'Herne. Jacques Derrida, Paris: Éditions de l'Herne, 521-541.

Derrida, J. (2004b). "Pardonner: l'impardonnable et l'imprescriptible". En: Mallet, Marie-Louise; Michaud, Ginette (éds). Cahier de l'Herne. Jacques Derrida. Paris: Éditions de l'Herne, 2004, 541-561.

Derrida, J. (2012). "La déconstruction et l'autre" en: Les Temps Modernes. n. 669-670, julio-octubre. pp. 7-29.

HeidegGer, M. (1975). Wegmarken, Frankfurt am Main: Vittorio Klostermann.

Heidegger, M. (1977a). Sein und Zeit, Frankfurt am Main: Vittorio Klostermann.

Heidegger, M. (1977b). Holzwege, Frankfurt am Main: Vittorio Klostermann.

Heidegger, M. (1981). Erläuteungen zu Hölderlins Dichtung, Frankfurt am Main: Vittorio Klostermann.

Heidegger, M. (1982). Parmenides, Frankfurt am Main: Vittorio Klostermann.

Heidegger, M. (1984). Hölderlins Hymne "Der Ister«, Frankfurt am Main: Vittorio Klostermann.

Heidegger, M. (1985). Unterwegs zur Sprache, Frankfurt am Main: Vittorio Klostermann.

Heidegger, M. (1991). Grundbegriffe, Frankfurt am Main: Vittorio Klostermann.

Heidegger, M. (1997). Der Satz vom Grund, Frankfurt am Main: Vittorio Klostermann.

Heidegger, M. (1999). Hölderlins Hymnen »Germanien« und "Der Rhein«, Frankfurt am Main: Vittorio Klostermann.

Heidegger, M. (2000). Vorträge und Aufsätze, Frankfurt am Main: Vittorio Klostermann.

Heidegger, M. (2002). Was Heisst Denken?, Frankfurt am Main: Vittorio Klostermann.

Heidegger, M. (2005). Über den Anfang, Frankfurt am Main: Vittorio Klostermann. 
Heidegger, M. (2007). Zur Sache des Denkens, Frankfurt am Main: Vittorio Klostermann.

JARAN, F. (2010). “De la différence entre l'histoire comme événement (Geschichte) et l'histoire comme science (Historie) chez Heidegger", en: Klesis - Revue Philosophique. n. 15, pp. 104-124.

Este trabajo se encuentra bajo una licencia de Creative Commons ReconocimientoNoComercial-SinObraDerivada 4.0 